\title{
CORRIGENDUM
}

\section{Enhanced absorption and carrier collection in Si wire arrays for photovoltaic applications}

Michael D. Kelzenberg, Shannon W. Boettcher, Jan A. Petykiewicz, Daniel B. Turner-Evans, Morgan C. Putnam, Emily L. Warren, Joshua M. Spurgeon, Ryan M. Briggs, Nathan S. Lewis and Harry A. Atwater

Nature Materials 9, 239-244 (2010); published online: 14 February 2010; corrected after print: 19 February 2010.

In the version of this Letter originally published, the first sentence in the Acknowledgements should have been: "This work was supported by BP and in part by the Department of Energy EFRC program under grant DE-SC0001293, and made use of facilities supported by the Center for Science and Engineering of Materials, an NSF Materials Research Science and Engineering Center at Caltech."

This has been corrected in the HTML and PDF versions of this Letter. 